\title{
HABILIDADES DE EVALUACIÓN CRÍTICA PARA LA MEJOR PRÁCTICA CLÍNICA
}

\section{Critical Appraisal Skills for Best Clinical Practice}

\author{
José Luis PARDAL-REFOYO \\ Hospital Universitario de Salamanca. Servicio de Otorrinolaringología y Cirugía de Cabeza y Cello. \\ Instituto de Investigación Biomédica de Salamanca (IBSAL). \\ Director de Revista ORL (Ediciones Universidad de Salamanca). Salamanca. España. \\ Correspondencia: jlpardal@usal.es
}

Fecha de publicación: 4 de enero de 2021

Fecha de publicación del fascículo: 1 de marzo de 2021

Conflicto de intereses: Los autores declaran no tener conflictos de intereses Imágenes: Los autores declaran haber obtenido las imágenes con el permiso de los pacientes Política de derechos y autoarchivo: se permite el autoarchivo de la versión post-print (SHERPA/RoMEO) Licencia CC BY-NC-ND. Licencia Creative Commons Atribución-NoComercial-SinDerivar 4.0 Internacional Universidad de Salamanca. Su comercialización está sujeta al permiso del editor

Dejamos atrás un año complicado en todos los ámbitos, en el social, en el económico, en el sanitario y con grandes repercusiones personales. El reto médico en el que nos encontramos nos pone a prueba en todos los niveles y tareas y va a condicionar nuestra actividad en 2021.

Durante 2020, entre las dificultades, Revista ORL ha continuado su labor editorial con progresos evidentes.

La actualización a la nueva versión del sistema OJS (Open Journal Systems) [1] ha sido un esfuerzo de Ediciones Universidad de Salamanca, que se ve recompensado por la mayor sencillez de la actividad editorial para todos, autores, revisores y editores. El nuevo sistema, además, permite relacionar la identidad de los autores con su identificador ORCID [2] lo que facilita que cada autor mantenga su información pública actualizada evitando confusiones con otros autores. También el nuevo sistema facilita la conexión con Publons [3] y de esta forma el acceso a revisores externos que sin duda mejorará la calidad de los contenidos de Revista ORL.

Además de su consolidación en ESCI-Wos (Emerging Sources Citation Index - Web of Science), Revista ORL ha sido indexada en SciELO (Scientific Electronic Library Online) y en el buscador BVS 


\section{HABILIDADES DE EVALUACIÓN CRÍTICA PARA LA MEJOR PRÁCTICA CLÍNICA \\ PARDAL-REFOYO J L}

(Biblioteca Virtual en Salud) [4-7]. WoS y BVS, con sus nuevos sistemas de búsqueda, ofrecen una potencia muy superior a otros buscadores biomédicos tradicionales porque comprenden literatura médica europea e iberoamericana además de Medline.

No podemos perder de vista el objetivo y misión de Revista ORL desde que nació en 2010: facilitar la publicación a los autores y la comunicación científica. La orientación a incrementar las revisiones bibliográficas y revisiones sistemáticas asociadas a cualquier otro tipo de artículo (especialmente casos clínicos o técnicas de diagnóstico o tratamiento) es probablemente la mejor forma de incrementar la difusión del conocimiento (en ocasiones asociado a cursos de formación como son la Reunión del Grupo de Otoneurología o el curso de Bases de Tiroidología y Paratiroidología en cirugía e tiroides y paratiroides [8] cuyas ponencias en artículos se publican en Revista ORL y que pretenden ser un ejemplo para el resto de actividades formativas).

La adaptación de la formación a formatos virtuales ha sido otro reto que hemos superado. Las jornadas JAsPE en su $8^{\text {a }}$ edición, celebradas en diciembre de 2020 por videoconferencia ha incrementado el número de participantes respecto a las ediciones presenciales y ha abierto posibilidades de trabajo multidisciplinar creándose un grupo de lectura crítica (GLC), que sin duda alguna va a ayudarnos a mejorar la actividad editorial y la calidad asistencial que ofrecemos a nuestros pacientes, objetivo último de la actividad médica en cualquiera de sus facetas. Los miembros del
GLC aportarán artículos de interés que se analizarán en al menos cuatro reuniones virtuales en directo acreditadas coordinadas por un experto en lectura crítica.

El título de este editorial resume el objetivo de este año que comenzamos con la certeza de que el entrenamiento en la lectura crítica nos ayudará a tomar las mejores decisiones ante problemas concretos y a incrementar y mejorar la calidad de los contenidos de Revista ORL.

En nombre del equipo editor de Revista ORL, solo me queda desear lo mejor para todos nuestros colaboradores y lectores en este año que comenzamos, y recordar que Revista ORL permanece atenta, abierta y comprometida como espacio de encuentro y colaboración.

\section{REFERENCIAS}

1. OJS-PKP: http://pkp.sfu.ca/ojs

2. ORCID: https://orcid.org/

3. Publons: https://publons.com/

4. ESCI-Wos. Emerging Sources Citation Index - Web of Science: http://www.webofknowledge.com

5. SciELO España - Scientific Electronic Library Online (isciii.es): http://scielo.isciii.es/scielo.php

6. Revista ORL. SciELO España: http://scielo. isciii.es/scielo.php?script=sci_serial\&pid=24447986\&lng=es\&nrm=iso

7. BVS (Biblioteca Virtual en Salud): https://bvsalud. org/es/

8. Curso Bases de Tiroidología y Paratiroidología en cirugía de tiroides y paratiroides. Web: http:// tiroides.org.es/ . Campus IBSAL: https://formacion.ibsal.es/ 